\title{
Use of Value Chain Mapping to Determine R\&D Domain Knowledge Retention Framework Extended Criteria
}

\author{
Mohamad Safuan Bin Sulaiman, Ariza Nordin, Nor Laila Md Noor, Wan Adilah Wan Adnan \\ Faculty of Computer and Mathematical Sciences \\ Universiti Teknologi MARA (UiTM) \\ Shah Alam, Malaysia
}

\begin{abstract}
Implementing a knowledge retention (KR) strategy is crucial to overcome the loss of expert knowledge due to employee turnover and retirement. The knowledge loss phenomenon caused organizations to face enormous risks which affect performance. KR frameworks and models are made available beyond research and development (R\&D) organizations, to address knowledge retention strategies for administrative, operational, and manufacturing organizations. For research-intensive portfolios within $R \& D$ organizations, using the available KR frameworks requires fitting. The difficulty to address knowledge loss due to the uniqueness of the R\&D organization's knowledge artifacts requires an extended KR framework. Before designing the extended KR framework, it is crucial to determine the framework's additional criteria. The paper reports the use of value chain mapping to determine the extended criteria of the KR framework fit for R\&D organizations. The value chain mapping method identifies the knowledge activities in the R\&D using Porter Value Chain (PVC) as the reference model. The output is a Knowledge Chain Model (KCM) that defines the critical points of knowledge loss in the R\&D value chain. These critical points are project-based expert critical knowledge focus, project-based tacit knowledge transfer, and project-based knowledge repository which are nominated extended criteria of the KR Framework fit for R\&D organizations.
\end{abstract}

Keywords-Knowledge retention framework; research and development; porter value chain; knowledge management; knowledge loss; research intensive portfolio; knowledge chain model

\section{INTRODUCTION}

Knowledge loss is a phenomenon that undeniably brings risk to organizational sustainability. The knowledge loss is spurred by either aging experts leaving the organization for retirement or expert or knowledgeable workers leaving for better job offers in other organizations. Knowledge loss is critical drawing much attention from the organizational knowledge management teams and risk managers to overcome the phenomenon using solutions pertaining to retention of critical knowledge loss. Despite having excellent KM practices in place, organizations still have a slimmer chance of facing critical knowledge loss [1].

Most of the studies of retention of critical knowledge loss were conducted on small and medium enterprises (SMEs), oil and gas, education, and manufacturing sectors $[2,3,4]$. These studies were more focused on the operational knowledge of the organizations. To address the critical knowledge loss in the organization, this research specificity focused on the critical knowledge loss in the research and development (R\&D) organizations. Like other organizations, R\&D organizations also face knowledge loss when their expert or knowledgeable researchers leave the organization. The loss indefinitely affects the performance of the R\&D organization since the absence of expert researchers' knowledge hinders the completion of remaining or future $R \& D$ projects. The need to understand knowledge loss in an $\mathrm{R} \& \mathrm{D}$ organization is important since $\mathrm{R} \& \mathrm{D}$ is a strategic investment to produce better and newly featured products of technology either in a business or government. Overlooking knowledge loss in R\&D organizations may be a strategic loss for the economic growth of a country. The current literature reported limited studies conducted for R\&D organizations to address the critical knowledge loss of R\&D activities.

The paper reports on a study to determine extended criteria required to fit the $\mathrm{KR}$ framework for an $\mathrm{R} \& \mathrm{D}$ organization. The use of value chaining mapping is elaborated to define criteria that are synthesized from the R\&D and knowledge chain analysis. This study used the Porter value chain (PVC) model as the basis to develop the $R \& D$ value chain and knowledge chain model (KCM) to identify the knowledge activities in the $R \& D$ value chain.

\section{LITERATURE REVIEW}

Knowledge Retention (KR) is one of the important KM and organizational strategies to minimize critical knowledge loss [5]. Many KR Frameworks and models were proposed to overcome the knowledge loss but there is a lack of focus being given to $\mathrm{KR}$ for $\mathrm{R} \& \mathrm{D}$ organizations. The literature review of this study consists of four parts. The first part discusses frameworks and models for retention of critical knowledge loss to help understand the issues and context of the existing setup of managing critical knowledge loss.

The second part focuses on the R\&D organizations to show the uniqueness of the organizations as compared to the operational-based organizations. The third part reviews the Porter Value Chain (PVC) model that is used in this study as the basis for synthesizing the R\&D value chain. The fourth part reviews the knowledge chain model that is used to map the 
knowledge activities with the $R \& D$ value chain. These reviews are towards the objective of identifying criteria that will be used as the foundation for the development of the KR framework for R\&D organizations.

\section{A. Frameworks and Models for Retention of Critical Knowledge in Organization}

Several frameworks related to KR were reviewed for this purpose. This study has reviewed the frameworks and models proposed by Arif, Egbu, Alom \& Khaflan [6], Boyles, Kirschnick, Kosilov, Yanev \& Mazour [7], Doan \& Rosenthalsabroux [8], Levy [1] and Wamundila and Ngulube [9]. The summary of the frameworks is shown in Table I.

Early work on the KR model [6] for the construction organizations is based on a case study performed at construction companies in the United Arab Emirates (UAE). This model proposed a method to assess the KR capabilities of an organization and suggests opportunities for improvement. The model emphasizes a four-stage KR process that covers socialization, codification, knowledge construction, and knowledge retrieval.

Similarly in the same year, Boyles, Kirschnick, Kosilov, Yanev \& Mazour [7] proposed a comprehensive cycle of retention processes in the case of retirement implemented in nuclear industries that emphasized several important stages that included (1) Conduct of risk assessment, (2) Determination and Implementation of the plan, (3) Monitoring and evaluation. Each process has sub-processes that further elaborate the retention of critical knowledge in detail. In addition, Boyles, Kirschnick, Kosilov, Yanev \& Mazour [7] suggested a dedicated and separate self-assessment process in the case of employees who are leaving and transferring to other organizations or departments.

Continuing work on KR is seen in the work of Levy [1] who proposed a retention framework that is based on case studies performed in Israel between 2007 and 2010. The case studies were performed in seven organizations in banking, ministerial- level of a government department, national services, and defense industries. The model consists of three main stages for retention, which focused on the implementation stage for vertical knowledge transfer and eliminates assessment stage. The stages include (1) Scope, (2) Transfer, and (3) Integration. In the context of the organization, Levy [1] has underlined three types of organizational response to the phenomena of knowledge loss which include (1) Avoidance, (2) Engagement, and (3) Reaction. In this context, Knowledge retention is in the need for Engagement and Reaction-type of organizations because of inappropriate $\mathrm{KM}$ practice at the organizational level.

Wamundila and Ngulube ([9] proposed a retention framework for higher education institutions which the case study was performed at the University of Zambia (UNZA). The proposed framework has focused on (1) Identifying KR challenges at the organizational level, (2) Acknowledge the need and purpose for $\mathrm{KR}$ at the organizational level, (3) Preparedness of tacit and explicit knowledge integration, (4) Understanding the dimensions of $\mathrm{KR}$ which primarily encompasses knowledge assessment, acquisition, and transfer.
TABLE I. SUMMARY OF COMPONENTS IN EXISTING KR FRAMEWORKS

\begin{tabular}{|c|c|}
\hline Authors & Components of the Framework \\
\hline $\begin{array}{l}\text { Arif et al. } \\
\text { (2009) [6] }\end{array}$ & $\begin{array}{l}\text { 1. Personalization/Socialization (Individual knowledge) } \\
\text { 2. Codification/ Externalisation (Conversion - Tacit to } \\
\text { Explicit) } \\
\text { 3. Combination (Organizational Memory: knowledge saved in } \\
\text { IT/ Support Systems) } \\
\text { 4. Internalisation (Retrieval - Explicit to Tacit: Retrieving } \\
\text { Knowledge for Reuse) }\end{array}$ \\
\hline $\begin{array}{l}\text { Boyles et } \\
\text { al. (2009) } \\
{[7]}\end{array}$ & $\begin{array}{ll}\text { 1. } & \text { Conduct Risk Assessment } \\
\text { 2. } & \text { Determine and Implement Plan } \\
\text { 3. } & \text { Monitor and Evaluate }\end{array}$ \\
\hline $\begin{array}{l}\text { Doan et al. } \\
\text { (2011) [8] }\end{array}$ & $\begin{array}{ll}\text { 1. } & \text { Top Management Support } \\
\text { 2. } & \text { ICT Tools } \\
\text { 3. } & \text { Knowledge Retention Process } \\
\text { 4. } & \text { Critical knowledge (Initiation, } \\
\text { 5. } & \text { Implementation and evaluation) } \\
\text { 6. } & \text { Business Process Focus } \\
\text { 7. } & \text { Human Resource Practices } \\
\text { 8. } & \text { Knowledge Retention Strategy } \\
\text { 9. } & \text { Learning Culture } \\
\end{array}$ \\
\hline $\begin{array}{l}\text { Levy } \\
\text { (2011) [1] }\end{array}$ & $\begin{array}{ll}\text { 1. } & \text { Initiating the process } \\
\text { 2. } & \text { Scope } \\
\text { 3. } & \text { Transfer } \\
\text { 4. } & \text { Integration } \\
\text { 5. } & \text { Structured Process } \\
\text { 6. } & \text { Structured Result } \\
\end{array}$ \\
\hline $\begin{array}{l}\text { Wamundila } \\
\text { and } \\
\text { Ngulube } \\
(2011)[9]\end{array}$ & $\begin{array}{l}\text { 1. Identify knowledge retention challenges } \\
\text { 2. Acknowledge need and purpose for knowledge } \\
\text { retention } \\
\text { 3. Integrate tacit and explicit knowledge } \\
\text { 4. Dimensions of knowledge retention (knowledge } \\
\text { assessment, acquisition, and transfer) }\end{array}$ \\
\hline
\end{tabular}

Doan \& Rosenthal-Sabroux [8] proposed a reference model of knowledge retention for Small and Medium-Sized Enterprises (SMEs). The model consists of several elements that are believed to be critical for an effective KR implementation. Doan \& Rosenthal-Sabroux [8] suggested the model can be used as a starting step of the KR initiative and as a template to assess the KR maturity level.

Based on the summary in Table I, all frameworks and models have variations of components which some have similar, and some have their unique components. In addition, data that have been acquired to propose the frameworks are mainly from operational-based organizations. Whilst an analysis by Sulaiman [10] has underlined several issues on the applicability and completeness of KR frameworks for knowledge-intensive organizations which found such limitations in the existing frameworks that lack of technology used to help the assessment process during the implementation of KR and lack of study had been done in R\&D organization and remain as recommendations for future exploration. These limitations have motivated this study to be conducted.

\section{B. Research and Development (R\&D) Organizations}

Research and development (R\&D) organization is an example of a knowledge-intensive organization where KR is deemed to be important. Before further discussion it is good to clarify the definitions of R\&D. Research is defined in a few categories which includes. 
1) Basic research that its objective to gain more complete knowledge of the studied subject without a specific application in mind with the advancement of scientific knowledge without working for long-term economic or social benefits and with no positive efforts to apply it (pure basic research) and produce a broad base of knowledge to form the background to the solution of problems (oriented basic research) without a specific commercial goal (oriented basic research) $[11,12]$.

2) Applied Research is the acquisition of knowledge to determine the means to achieve a specific and recognized need by discovering new scientific knowledge that has specific commercial objectives concerning products, processes, or services [11,12].

Development is defined as the systematic use of the knowledge or understanding gained from research, directed toward the production of useful materials, devices, systems, or methods, including the design and development of prototypes and processes. [11]. It is also called experimental development which means a systematic work, drawing on existing knowledge gained from research and practical experience that is directed to producing new materials, products, and devices; to installing new processes, systems, and services; or to improving substantially those already produced or installed [12].

$\mathrm{R} \& \mathrm{D}$ is found to be the most important component in any part of modern businesses that creates new, robust, and better products, processes, and the way people do things. Elements of $R \& D$ in the organizations and firms have a strong influence on the success rate in their business and help them gain a competitive advantage over other firms [13].

$R \& D$ also plays important role in the economic sector in a nation, making a profit in business enterprise, effective in technology-based governmental agencies (e.g., the US Department of Defence), and the higher investment in R\&D activities by a nation ( $\$ 355$ billion in the United States in 2007), [14]. Korea is one of the many examples, where R\&D spending is on more advanced industries that foster productivity growth and proven that the productivity impact of $\mathrm{R} \& \mathrm{D}$ is stronger in more high-tech industries and during economic downturns [15].

$R \& D$ organizations are different from other organizations based on four elements 1) People, 2) Ideas, 3) Funds and 4) Culture [14]. Managing an R\&D organization is not simple and good management of research is not only the critical difference among the organizations, but the research itself is the most difficult to manage as compared to other functional activities [14].

The importance of $R \& D$ and the uniqueness of $R \& D$ organizations due to their people, ideas, funds, and culture raise the need to further explore KR in R\&D organizations. This agrees with the findings from Sulaiman [10] who also suggested the need to further explore $K R$ in the $R \& D$ organization. As a first step, it is necessary to identify where critical knowledge loss could occur in R\&D organizations before addressing the KR of R\&D organizations. For this purpose, the Porter value chain (PVC) and knowledge chain model (KCM) analyses can be used to identify the critical knowledge loss in $\mathrm{R} \& \mathrm{D}$ organization value chain activities. $\mathrm{PVC}$ and $\mathrm{KCM}$ are further elaborated in the following subsections.

\section{Porter Value Chain (PVC)}

Porter [16] introduced the value chain concept to describe a set of activities that an organization carries out to add value to its customer. The concept is now formally known as the Porter value chain (PVC) and is an established mechanism to understand the value chain in operational, business, and manufacturing organizations. Various authors have used the PVC in their research settings ever since. Relating to the knowledge value chain, the PVC has been used by Holsapple and Singh [17] for mapping a proposed knowledge chain model and Jordan et al. [18] used PVC as the basis for the product value chain in his framework for evaluating R\&D impact and supply chain.

The PVC model consists of nine value-adding activities with five primary and four secondary activities toward competitive advantage as illustrated in Fig. 1.

The primary value-added activities consist of inbound logistics, operations, outbound logistics, marketing and sales, and service and are defined as in Table II.

The secondary activities (Table II) involve corporate infrastructure, human resource management, technology development, and procurement. In the primary activities, that PVC shows the important value-added at each stage starting from input materials until the finished product that can be marketed. While secondary activities are in support of the whole range of primary activities.

The mapping of PVC to specific organization activities highlights the value-added at each phase of the organization's primary activities and identifies the organization's competitive advantage. The mapping of PVC activities to organizational value chain was used by Tomasevic and Stojanovic [19] and Sobotka [20] for educational institutions and Rapcevi [21] for public sectors.

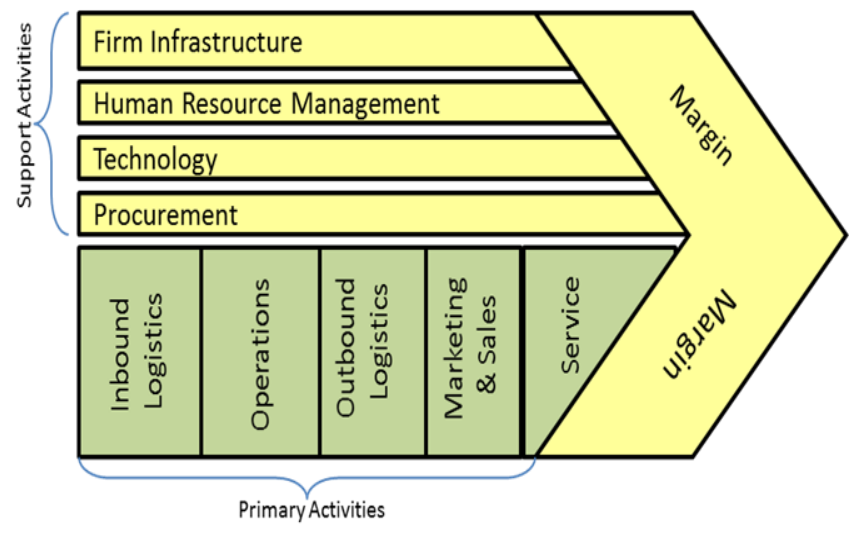

Fig. 1. Porter Value Chain (PVC) Model. 
TABLE II. DEFINITION OF THE PVC ACTIVITIES

\begin{tabular}{|c|c|}
\hline Activity & Definition \\
\hline \multicolumn{2}{|l|}{ Primary } \\
\hline 1. Inbound Logistics & $\begin{array}{l}\text { Receiving, storing, and distributing materials } \\
\text { to manufacturing premises. }\end{array}$ \\
\hline 2. Operations & Transforming inputs into finished products \\
\hline 3. Outbound Logistics & Storing and distributing products \\
\hline 4. Marketing and Sales & Promotion and sales efforts \\
\hline 5. Service & $\begin{array}{l}\text { Maintain or enhance product value through } \\
\text { post-sale services }\end{array}$ \\
\hline \multicolumn{2}{|l|}{ Secondary } \\
\hline 1. Corporate Infrastructure & $\begin{array}{l}\text { Support for the entire value chain including } \\
\text { general management, planning, finance, } \\
\text { accounting, legal services, government } \\
\text { affairs, and quality management }\end{array}$ \\
\hline $\begin{array}{l}\text { 2. Human Resource } \\
\text { Management }\end{array}$ & $\begin{array}{l}\text { Recruiting, hiring, training, and development } \\
\text { of employees }\end{array}$ \\
\hline 3. Technology Development & $\begin{array}{l}\text { Improving product and manufacturing } \\
\text { process }\end{array}$ \\
\hline 4. Procurement & Purchasing input \\
\hline
\end{tabular}

\section{Knowledge Chain Model (KCM)}

The KCM was proposed by Holsapple and Singh [17] and was based on a descriptive KM framework developed via a Delphi study involving an international panel of prominent KM practitioners and academicians [22]. The model has five primary and four secondary $\mathrm{KM}$ activities in the $\mathrm{KCM}$ as in Fig. 2 [23].

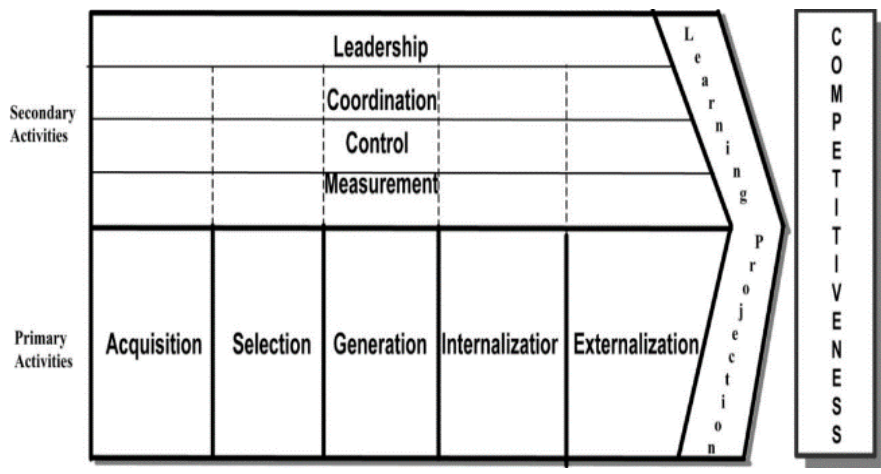

Fig. 2. Knowledge Chain Model (KCM).

Five primary KM activities include Knowledge acquisition, selection, generation, internalization, and externalization, and four secondary KM activities include knowledge leadership, coordination, control, and measurement. The definition of the primary and secondary KM activities is in Table III.

The reviewed KR frameworks from previous works are different from one another. The differences have shown the gaps between the frameworks. A small but important gap has shown that a lack of data was acquired from $R \& D$ organizations as the basis of producing the existing KR Framework. Therefore, the importance and unique characteristics of $R \& D$ organizations are reviewed and have shown some differences between operational-based and R\&D organizations. The reviewed PVC model has shown the useful technique to derive the $R \& D$ organization value chain activities as been used in the operational-based organization as well as another mapping for the organizational value chain. While KVC is reviewed, to address important knowledge activities at the organizational level that might lead to critical knowledge loss.

TABLE III. DEFINITION OF THE PRIMARY AND SECONDARY KM ACTIVITIES

\begin{tabular}{|c|c|}
\hline Primary Activities & Secondary Activities \\
\hline $\begin{array}{l}\text { Knowledge Acquisition: } \\
\text { Acquiring knowledge from } \\
\text { external sources and making it } \\
\text { suitable for subsequent use. } \\
\text { Knowledge Selection: } \\
\text { Selecting needed knowledge } \\
\text { from internal sources and making it } \\
\text { suitable for subsequent use. } \\
\text { Knowledge Generation: } \\
\text { Producing knowledge by either } \\
\text { discovery or derivation from existing } \\
\text { knowledge. } \\
\text { Knowledge Internalization: } \\
\text { Altering the state of an } \\
\text { organization's knowledge resources } \\
\text { by distributing and storing acquired, } \\
\text { selected, or generated knowledge. } \\
\text { Knowledge Externalization: } \\
\text { Embedding knowledge into } \\
\text { organizational output for release into } \\
\text { the environment. }\end{array}$ & $\begin{array}{l}\text { Knowledge Leadership: } \\
\text { Establishing conditions that } \\
\text { enable and facilitate fruitful conduct } \\
\text { of KM } \\
\text { Knowledge Coordination: } \\
\text { Managing dependencies among } \\
\text { KM activities to ensure that proper } \\
\text { processes and resources are brought } \\
\text { to bear adequately at appropriate } \\
\text { times } \\
\text { Knowledge Control: } \\
\text { Ensuring that needed } \\
\text { knowledge processors and resources } \\
\text { are available in sufficient quality, } \\
\text { subject to security requirement } \\
\text { Knowledge Measurement: } \\
\text { Assessing values of knowledge } \\
\text { resources, knowledge processors, } \\
\text { and their deployment }\end{array}$ \\
\hline
\end{tabular}

\section{Methodology}

The research method employed is a two-step procedure that focused on (1) the PVC mapping on R\&D processes to produce $\mathrm{R} \& \mathrm{D}$ organization value chain activities and (2) the knowledge chain model mapping on R\&D organization knowledge chain activities to identify possible loss of critical R\&D knowledge.

The PVC mapping on R\&D processes was conducted based on the R\&D processes as described by several kinds of literature that include the work of [23-29]. An interpretive analysis based on PVC is then used to map the operationalbased organization with the $R \& D$ organization value chain. This analysis is purposely to identify the differences between operational-based and $\mathrm{R} \& \mathrm{D}$ organizations and produce the $R \& D$ organization value chain.

In the next step, the knowledge chain model by Holsapple and Singh [17] is used to map each R\&D organization's value chain activities with knowledge activities. The result of the mapping is used to identify knowledge activities at each R\&D value chain activity that might lead to the possible loss of critical R\&D knowledge.

By knowing the critical point of R\&D knowledge loss from the findings of those mappings, several criteria for retention of critical knowledge loss would be suggested for KR Framework in $R \& D$ organizations. 


\section{DATA AND ANALYSIS}

The mapping of PVC onto the R\&D organizational process is mainly used in $R \& D$ standard processes [26]. The R\&D standard processes are well-structured and similar to the PVC structure [26].

Standard R\&D processes into two levels: the organizational level and the project level [26]. The organizational level contains organizational processes such as R\&D Planning, Portfolio Management, Idea Management, Intellectual Property Management, Infrastructure Management, Human Resource Management, Organizational Performance Management, and Quality Management The structure of the standard R\&D processes at the organizational level is shown in Fig. 3.

The project level contains support processes and fulfillment processes. Support processes consist of Project Planning, Project Monitoring, Gate Assessment, Collaboration Mgt. and Risk Mgt. while, fulfillment processes consist of Concept Modelling, Business Feasibility, Specification Definition, Design, Development, Prototype, Market Test, and Market Launch. The standard R\&D processes at the project level are shown in Fig. 4.

Besides standard process mapping [26], some other R\&D processes are also considered in the mapping includes $[27,28,28]$ to support the works from Yoon, Lee, Lee \& Yoon [26] and some have additional perspectives [28] Table IV shows the summary of R\&D processes, used in this mapping.

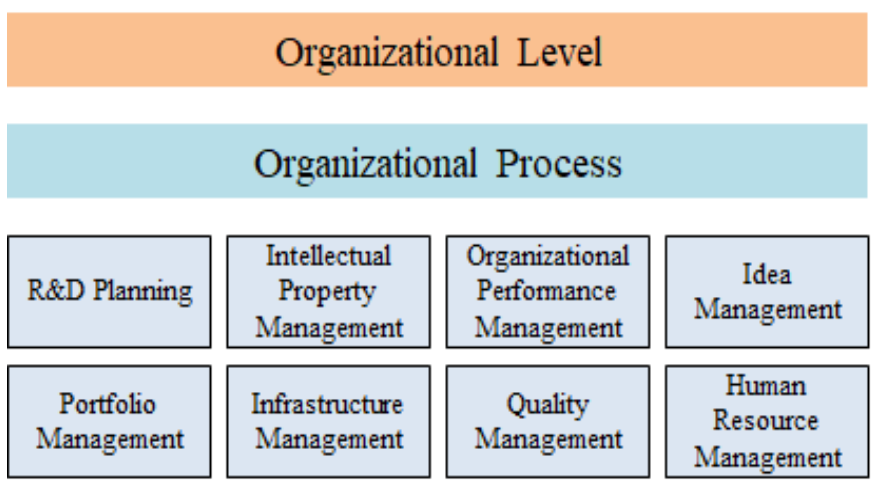

Fig. 3. Standard R\&D Processes at the Organizational Level.

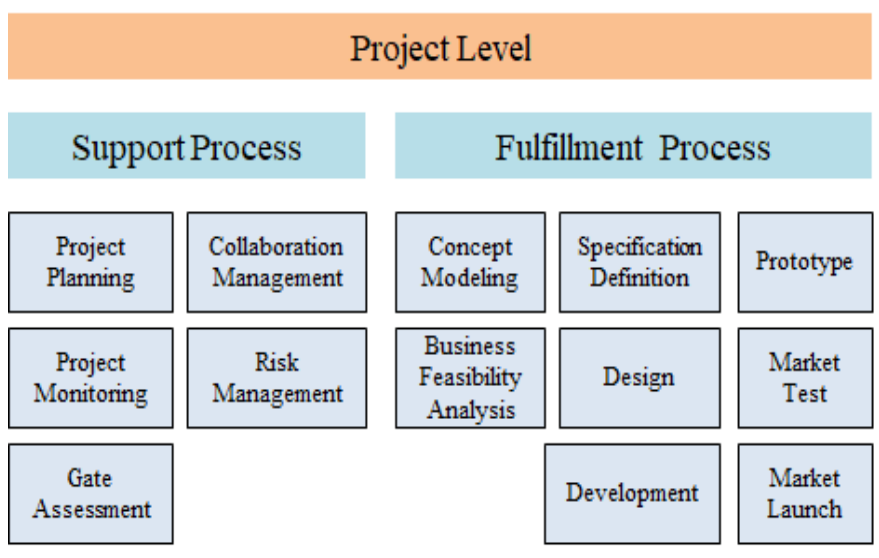

Fig. 4. Standard R\&D Processes at the Project Level.
TABLE IV. SUMMARY OF R\&D COMPONENTS AND PROCESSES

\begin{tabular}{|c|c|c|}
\hline Authors & $\begin{array}{l}\text { R\&D Components/ } \\
\text { Processes }\end{array}$ & /Processes \\
\hline $\begin{array}{l}\quad \text { Yoon, } \\
\text { Lee, Lee } \\
\text { \& Yoon. } \\
\text { (2015) }[26]\end{array}$ & $\begin{array}{ll}\text { - } & \text { Organizational } \\
& \text { Process } \\
\text { - } & \text { Support Process } \\
\text { - } & \text { Fulfillment Process }\end{array}$ & $\begin{array}{l}\text { - R\&D Planning } \\
\text { - Portfolio Mgt. } \\
\text { - Idea Mgt. } \\
\text { - Intellectual Property Mgt. } \\
\text { - Infrastructure Mgt. } \\
\text { - Human Resource Mgt. } \\
\text { - Organizational Performance } \\
\text { Mgt. } \\
\text { - Quality Mgt. } \\
\text { - Project Planning } \\
\text { - Project Monitoring } \\
\text { - Gate Assessment } \\
\text { - Collaboration Mgt. } \\
\text { - Risk Mgt. } \\
\text { - Concept Modeling } \\
\text { - Business Feasibility } \\
\text { - Spesification Definition } \\
\text { - Design } \\
\text { - Development } \\
\text { - Prototype } \\
\text { - Market Test } \\
\text { - Market Launch }\end{array}$ \\
\hline $\begin{array}{r}\text { Martin } \\
\text { (2014) [28] }\end{array}$ & $\begin{array}{ll}\text { - } & \text { Foster Ideas } \\
\text { - } & \text { Focus Ideas } \\
\text { - } & \text { Pevelop Ideas } \\
\text { - } & \text { Regulatorype And Trials } \\
& \text { Marketing, And } \\
& \text { Product Development } \\
& \text { Activities } \\
\text { - } & \text { Launch }\end{array}$ & \\
\hline $\begin{array}{l}\quad \text { Kalyp } \\
\text { so (2018) } \\
{[27]}\end{array}$ & - $\quad \mathrm{R} \& D \backslash S t r a t e g y$ & $\begin{array}{l}\text { - Portfolio Management } \\
\text { - Innovation } \\
\text { - Project Management } \\
\text { - Ip Management } \\
\text { - Sourcing } \\
\text { - Talent Management } \\
\text { - Regulatory Compliance } \\
\text { - R\&D Operation }\end{array}$ \\
\hline $\begin{array}{r}\quad \text { Rouss } \\
\text { elon Saadn } \\
\text { \& Erickson } \\
\text { (1991) [29] }\end{array}$ & $\begin{array}{ll}\text { - } & \text { Priority Setting } \\
\text { - } & \text { Portfolio } \\
\text { - } & \text { Management } \\
\text { - } & \text { Project Management } \\
\end{array}$ & $\begin{array}{l}\text { - Program Analysis } \\
\text { - Portfolio Analysis } \\
\text { - Portfolio Adjustment } \\
\text { - Portfolio Assignment } \\
\text { - Project Planning } \\
\text { - Project Budgeting } \\
\text { - Manpower/Resource Planning } \\
\text { - Scheduling } \\
\text { - Active Monitoring } \\
\text { - Project Analysis } \\
\text { - Technology Forecasting } \\
\text { - Strategic Planning } \\
\text { - Market Forecasting }\end{array}$ \\
\hline
\end{tabular}


Based on some similar structures that exist in secondary activities on PVC and R\&D standard processes [26], this study focused the analysis on the primary activities (PVC) and R\&D standard processes at the project level. Each R\&D process in Table III is grouped based on the PVC activities. However, the mapping of the R\&D processes into PVC activities is rather difficult because the definition of inbound logistics, operations, and outbound logistics is more focused on the product. Therefore, some adjustments on the terminology of the value chain activities and definitions are suggested because R\&D standard processes are more focused on the research project rather than the product itself. For Inbound Logistics, Operations, Outbound Logistics, and Marketing and Sales, new terminology of the value chain activities for $R \& D$ are $R \& D$ Inputs, R\&D Work Processes, R\&D Outputs, and Realization respectively. The result of the mapping is shown in Table IV and the adjustment on the definition is suggested as follows:

- R\&D Inputs: Inputs to the research project that is needed to conduct Research Activities such as project team member, planning, and funding.

- R\&D Work Processes: Activities needed to achieve the objective of the research project such formulation of the research project, development of ideas, data collection, development of concept, model, theories by utilizing the research input.

- R\&D Outputs: The output of the research project such as patents, Innovations, products, and publications acquired from research activities.

- Realization: Established and tested R\&D output such as products and processes are packaged to be marketed and applied to targeted industries and commercialize the application of the Research Output to many industries.

- Service: Activities of maintaining the R\&D output such as marketed product and processes or usually called after-sales service.

Table $\mathrm{V}$ indicates the mapping of the $\mathrm{R} \& \mathrm{D}$ processes onto the PVC components and is based on the above definitions. Mapping Inbound Logistics onto R\&D Inputs include business feasibility, specification definition, portfolio analysis, portfolio adjustment, portfolio assignment, and sourcing.

R\&D Work Processes include project monitoring and analysis, concept modeling, design, development, scheduling, active monitoring, R\&D operation, fostering and developing ideas, prototype and trials, product development activities, and gate assessment.

R\&D Outputs include Innovation and Intellectual Property and mapping Marketing \& Sales onto Realization include market launch, test, and forecasting, launch, and marketing.

Based on the mapping analysis, it can be understood, Inbound Logistics can be mapped with Research Inputs, Operations with R\&D Work Processes, and Outbound Logistics with Research Outputs and Marketing and Sales, with Research Realization [30].
TABLE V. MAPPING R\&D PROCESSES ONTO PORTER VALUE CHAIN (PVC)

\begin{tabular}{|c|c|c|c|c|}
\hline \multicolumn{5}{|c|}{ Primary Activities (Project Level) } \\
\hline $\begin{array}{l}\text { Inbound } \\
\text { logistics }(R \& D \\
\text { Input) }\end{array}$ & $\begin{array}{l}\text { Operations } \\
\text { (R\&D Work } \\
\text { Processes) }\end{array}$ & $\begin{array}{l}\text { Outbound } \\
\text { logistics } \\
\text { (R\&D } \\
\text { Output) }\end{array}$ & $\begin{array}{l}\text { Marketing } \\
\text { \& Sales } \\
\text { (Realization) }\end{array}$ & $\begin{array}{l}\text { Servi } \\
\text { ce }\end{array}$ \\
\hline $\begin{array}{l}\text { Business } \\
\text { Feasibility }\end{array}$ & $\begin{array}{l}\text { Project } \\
\text { Monitoring }\end{array}$ & Innovation & $\begin{array}{l}\text { Market } \\
\text { Launch }\end{array}$ & \\
\hline $\begin{array}{l}\text { Specification } \\
\text { Definition }\end{array}$ & $\begin{array}{l}\text { Concept } \\
\text { Modelling }\end{array}$ & $\begin{array}{l}\text { Intellectual } \\
\text { Property }\end{array}$ & Market Test & \\
\hline $\begin{array}{l}\text { Portfolio } \\
\text { Analysis }\end{array}$ & Design & & $\begin{array}{l}\text { Market } \\
\text { forecasting }\end{array}$ & \\
\hline $\begin{array}{l}\text { Portfolio } \\
\text { adjustment }\end{array}$ & Development & & Launch & \\
\hline $\begin{array}{l}\text { Portfolio } \\
\text { assignment }\end{array}$ & Prototype & & Marketing & \\
\hline \multirow[t]{10}{*}{ Sourcing } & Scheduling & & & \\
\hline & $\begin{array}{l}\text { Active } \\
\text { Monitoring }\end{array}$ & & & \\
\hline & $\begin{array}{l}\text { Project } \\
\text { Analysis }\end{array}$ & & & \\
\hline & $\begin{array}{l}\text { R\&D } \\
\text { Operation }\end{array}$ & & & \\
\hline & Foster Ideas & & & \\
\hline & Focus Ideas & & & \\
\hline & $\begin{array}{l}\text { Develop } \\
\text { Ideas }\end{array}$ & & & \\
\hline & $\begin{array}{l}\text { Prototype and } \\
\text { trials }\end{array}$ & & & \\
\hline & $\begin{array}{l}\text { Product dev. } \\
\text { activities }\end{array}$ & & & \\
\hline & $\begin{array}{l}\text { Gate } \\
\text { Assessment }\end{array}$ & & & \\
\hline
\end{tabular}

None of the R\&D processes could be mapped onto the service activities because it is not part of $R \& D$ processes and usually under the technical department after the technology has been transferred within a period. The result of the mapping is shown in Fig. 6.

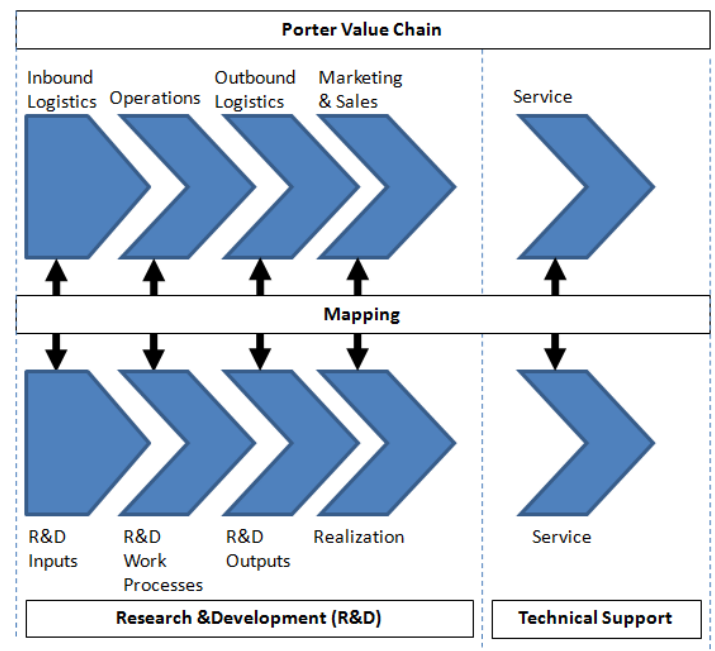

Fig. 5. Result of the PVC Mapping onto R\&D Processes. 
As referred to Fig. 5, four primary value chain activities for the $R \& D$ value chain were identified which include $R \& D$ inputs, R\&D work processes, R\&D Outputs, and Realization. Whilst Service is more towards technical support and was not considered as part of $R \& D$ processes. As a result, the proposed R\&D value chain is as in Fig. 6.

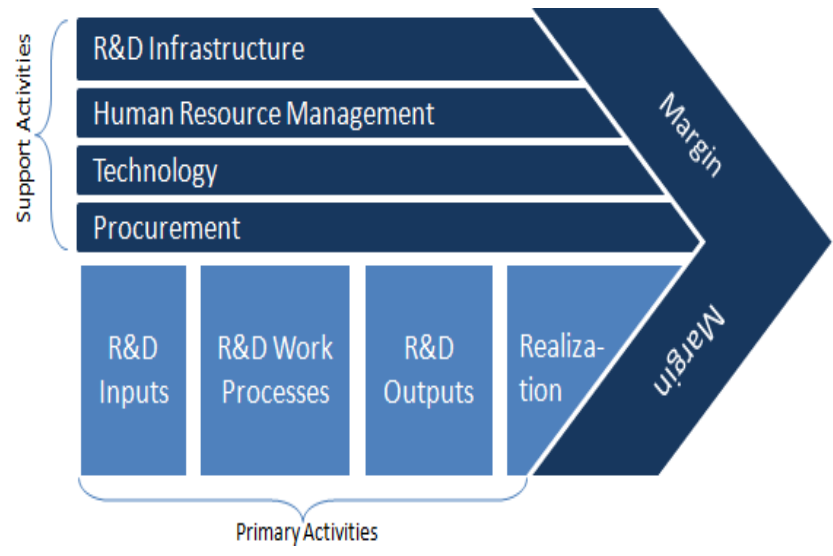

Fig. 6. The R\&D Organization Value Chain.

The primary activities in the R\&D organization value chain as in Fig. 6 are then mapped with the knowledge chain model to identify the point of critical R\&D knowledge loss. The knowledge chain model (KCM) of Holsapple and Singh [17] is used in this study to identify knowledge chain activities in each of the R\&D value chain activities. The definition of each primary knowledge chain activity is suggested by Holsapple and Singh [17] as in Table III.

From the definition of primary knowledge chain activities, it is understood, each $R \& D$ value chain has at least one knowledge chain activity. Knowledge acquisition and selection occur at R\&D Inputs, knowledge generation and internalization occur at R\&D Work Processes Activities, knowledge generation and externalization occur at R\&D Outputs and knowledge externalization occurs at Realization. The result of the mapping of knowledge value chain activities on $R \& D$ value chain activities is shown in Fig. 7.

At this stage, each $R \& D$ value chain activity has knowledge activities and at some R\&D activities, it produces and generates new knowledge.

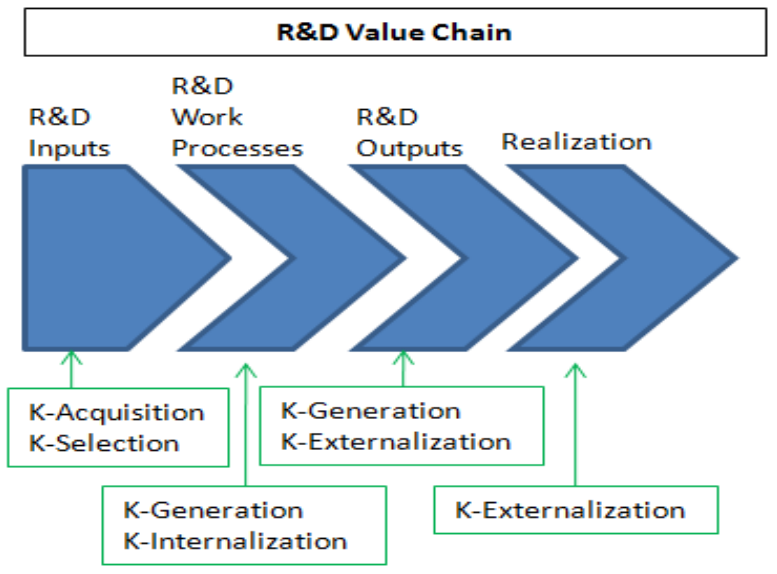

Fig. 7. R\&D Value Chain and Knowledge Chain Activities.

\section{DISCUSSION}

As this study is focusing on the criteria for knowledge retention framework, further discussion on the context of knowledge aspects for retention of critical knowledge in $R \& D$ organization which is based on the $R \& D$ value chain and knowledge activities is relevant.

From the analysis of mapping PVC onto R\&D Processes, it is discovered that the R\&D organization's value chain has different primary activities with similar support activities. These can be seen in the adjustment of the definitions at the primary activities as well as the absence of the R\&D process at Service activity. The differences proved that $R \& D$ and operational-based organization is different obviously at the primary activities which perhaps the existing KR framework is not fit for R\&D organizations.

From the KCM mapping onto primary $R \& D$ value chain activities, it is found that knowledge activities occur in each $\mathrm{R} \& \mathrm{D}$ value chain activity. It is also believed that each knowledge activity such as knowledge acquisition, selection, generation, internalization, and externalization has intensively and extensively occurred from the beginning until the end of the $R \& D$ projects.

R\&D Project team which is considered as R\&D knowledge workers play an important role in each R\&D and its knowledge activities. In addition, an expert in the project team plays a more significant role in the R\&D project. According to Joe, Yoong \& Patel [31], "experts are a powerful source of value creation within organizations and are people who have deep specialized knowledge of a subject, who are tested and trained, especially by experience. Expert demonstrates higher levels of efficiency, performs tasks with greater accuracy and costeffectiveness and holds subject-specific knowledge, such as on methods and procedures, including knowledge of how to deal with problems and new situations". Expert knowledge is also a valuable organizational resource [32]. To a certain extent, the experts often do not realize that they possess unique valuable knowledge, and for cognitive reasons, they are not able to express this knowledge [33]. In the situation, if an expert suddenly leaves the organization during the development of a prototype, where the knowledge generation is just started to be implemented and no one has the capability similar or nearly like the expert, it is critical and affects the project progress as well the performance of the R\&D organization. This implies that an $R \& D$ expert is one of the critical points to be seriously considered for the criteria of KR in R\&D organizations.

By looking into the $R \& D$ value chain and its knowledge activities, the tacit and explicit knowledge of each $R \& D$ project team will possibly accumulate over time and at each R\&D value chain activity. The knowledge of the team gradually and proportionally increased over time and chain activities. It means that knowledge accumulated at $R \& D$ Outputs activities is more than knowledge accumulated at R\&D Inputs. The knowledge accumulated over time and value chain activities is an asset to the organization. Losing experts or project team members at the final stage of the R\&D value chain activities are more critical than at the earlier R\&D stages because more efforts and resources must be invested to make the project progress as planned. Therefore, the accumulated 
knowledge over time and $R \& D$ chain activities is found to be important to be seriously considered where some strategic action could be possibly done to capture the knowledge as it progressed.

From the above arguments, expert knowledge and accumulated R\&D project knowledge are two important factors to be seriously considered for the criteria setting of $\mathrm{KR}$ Framework for R\&D organization based on the following findings:

- R\&D organizations are expertise-oriented and not solely product-oriented organizations. Therefore, in the context of retention of critical knowledge loss, more focus should be given to expert knowledge instead of knowledge of the product and innovation of the R\&D projects at every $R \& D$ value chain activity.

- Each R\&D project must have project team members that manage the accumulated R\&D project knowledge at each $R \& D$ value chain activity. The accumulated knowledge in each $R \& D$ value chain is important starting from the R\&D Inputs until Realization activities and it should be easily stored and transferred.

- Each project team consists of several persons that might have specific and diversified knowledge of the working R\&D projects and come from different generations. Transfer and sharing activities of tacit knowledge between members should be_done as early as at the R\&D Inputs to prevent knowledge loss.

- Each R\&D value chain activity has its knowledge activities which might hold the critical point of losing R\&D knowledge due to retirement, aging, and turnover factors. Therefore, each $R \& D$ project shall have documentation at every $R \& D$ value chain activity and stored in organizational memory to prevent the loss of explicit knowledge.

\section{PROPOSED CRITERIA FOR KR FRAMEWORK}

Based on the previous findings derived from the PVC and $\mathrm{KCM}$ analyses in Section $\mathrm{V}$, this study underlines several criteria on the perspective of critical R\&D knowledge loss to be used as the basis of developing the KR Framework for R\&D organizations. Details of the criteria are as follows:

- Focused on the KR should be given to the retention of the R\&D expert knowledge and potential project team that might leave the organization. Therefore, the KR Framework for R\&D organization should have a thorough assessment component and shall be focusing on the critical R\&D expert knowledge so that the potential leaving critical experts or members of the project team and a successor could be easily identified and risk of losing the critical knowledge of the project team could be minimized and retained as early as possible. It is also recommended to use some technology [34], to assist the preparation of the assessment process and prevent the waste of organizational resources [10].
- For expert knowledge transfer, the minimum knowledge gap between an expert and a successor and within the R\&D project team would be a possible chance of easy transfer of critical knowledge. Therefore, the KR framework for R\&D organizations should consider mapping and binding experts and successors for tacit knowledge transfer. In the case of the expert and successor have multiple R\&D projects. The transfer shall be based on the project's point of view.

- For accumulated R\&D project knowledge, each knowledge activity in $R \& D$ value chain activities should retain the $R \& D$ project as it's progressed to minimize critical knowledge loss due to retirement and employee turnover. Therefore, the KR framework should consider a mechanism for easy transfer, store and retrieve $R \& D$ project knowledge as the project progressed. It is also important to consider the use of technology so that knowledge stored procedure would be easily reinforced, and the organizational memory would be easy and well-structured, and organized.

\section{CONCLUSION AND FUTURE WORK}

Most studies on KR frameworks are based on operationalbased organizations and a lack of focus had been given to R\&D-based organizations. As a first step towards KR frameworks for R\&D organizations, the first part of this study used mapping of PVC onto R\&D processes to identify the differences between both organizations. From the mapping analysis, the differences were found at primary activities of both organizations and proposed an $\mathrm{R} \& \mathrm{D}$ organization value chain. The second part of this study used the mapping of KCM onto the proposed $\mathrm{R} \& \mathrm{D}$ organization value chain to identify knowledge chain activities in the $R \& D$ value chain. From the KCM mapping analysis, expert and accumulated $R \& D$ knowledge factors were identified as a critical point of potential R\&D knowledge loss. Several criteria used as a basis for the development of the KR framework for $R \& D$ organizations were proposed which were based on several findings from the result of the mapping analyses.

Some empirical study is suggested for future works to further extend and examine the findings and streamline the recommended criteria of the KR framework for $R \& D$ organizations.

\section{ACKNOWLEDGMENT}

Special thanks to the Government of Malaysia, Malaysian Nuclear Agency, and Faculty of Computer and Mathematical Sciences, Universiti Teknologi MARA (UiTM) for support during the conduct of this study.

\section{REFERENCES}

[1] Levy M. Knowledge retention: minimizing organizational business loss. Journal of Knowledge Management. 2011 Jul 19.

[2] Ramona T, Alexandra B. Knowledge retention within small and medium-sized enterprises. Studies in Business and Economics. 2019 Dec 1;14(3):231-8.

[3] Haughton R. Exploring knowledge retention strategies to prevent knowledge loss in project-based organizations (PBOs) (Doctoral dissertation, Walden University). 
[4] Sumbal MS, Tsui E, Durst S, Shujahat M, Irfan I, Ali SM. A framework to retain the knowledge of departing knowledge workers in the manufacturing industry. VINE Journal of Information and Knowledge Management Systems. 2020 Jan 10.

[5] Sanz R, Hovell J. Knowledge retention framework and maturity model: improving an organization or team's capability to retain critical knowledge. Knowledge Management for Development Journal. 2021 Aug 28;16(1):8-27.

[6] Arif M, Egbu C, Alom O, Khalfan MM. Measuring knowledge retention: a case study of a construction consultancy in the UAE. Engineering, Construction, and Architectural Management. 2009 Jan 9.

[7] Boyles JE, Kirschnick F, Kosilov A, Yanev Y, Mazour T. Risk management of knowledge loss in nuclear industry organizations. International Journal of Nuclear Knowledge Management. 2009 Jan 1;3(2):125-36.

[8] Doan QM, Grundstein M, Rosenthal-Sabroux C. A reference model for knowledge retention within small and medium-sized enterprises.2011.

[9] Wamundila S, Ngulube P. Enhancing knowledge retention in higher education: A case of the University of Zambia. South African Journal of Information Management. 2011 Jan 1;13(1):1-9.

[10] Sulaiman MS, Abdul R, Nordin A, Noor NL. Improving Knowledge Preservation Strategy at Organizational Level through Knowledge Loss Risk Assessment (KLRA). 2016.

[11] National Science Board.Science and Engineering Indicators 2008, Two volumes (1, NSB 08-01; 2, NSB 08-01A). Arlington, VA: National Science Foundation.2008.

[12] Manual O. The measurement of scientific and technological activities. Proposed Guidelines for Collecting and Interpreting Technological Innovation Data. 2005 Jul;30.

[13] Liu O, Wang J, Ma J, Sun Y. An intelligent decision support approach for reviewer assignment in $R \& D$ project selection. Computers in Industry. $2016 \mathrm{Feb}$ 1;76:1-0.

[14] Jain R, Triandis HC, Weick CW. Managing research, development and innovation: Managing the unmanageable. John Wiley \& Sons; 2010 Jun 18.

[15] Lee D. Role of R\&D in the productivity growth of Korean industries: Technology gap and business cycle. Journal of Asian Economics. 2016 Aug 1;45:31-45.

[16] Porter, M. (1985) Competitive Advantage, New York: The Free Press.

[17] Holsapple CW, Singh M. The knowledge chain model: activities for competitiveness. Expert systems with applications. 2001 Jan 1;20(1):7798.

[18] Jordan G, Mote J, Ruegg R, Choi T, Becker-Dippmann A. A Framework for Evaluating R\&D Impacts and Supply Chain Dynamics Early in a Product Life Cycle. Looking inside the black box of innovation. Lawrence Berkeley National Lab.(LBNL), Berkeley, CA (United States); 2014 Jun 1.
[19] Tomašević I, Stojanović D, Simeunović B, Radović M, Andrić-Gušavac B. Creating Value in Higher Education Institutions. InToulon-Verona Conference" Excellence in Services" 2015 Aug 25.

[20] Sobotka B. Value chain in education sector illustrated with an example of Vocational Competence Certificate System. InForum Pedagogiczne 2016 (Vol. 2, pp. 305-316). Wydawnictwo Uniwersytetu Kardynała Stefana Wyszyńskiego w Warszawie.

[21] Rapcevičienė D. Modeling a value chain in public sector. Social Transformations in Contemporary Society. Disponible en (último acceso noviembre de 2017): http://stics. mruni. eu/wpcontent/uploads/2014/08/STICS_2014_2_42-49. pdf. 2014.

[22] Davè KP. An investigation of knowledge management characteristics: Synthesis, Delphi study, analysis. University of Kentucky; 1998.

[23] Lee CC, Yang J. Knowledge value chain. Journal of management development. 2000 Nov 1.

[24] Saha A. Mapping of Porter's value chain activities into business functional units. Management Innovation Exchange. Retrieved on September. 2011;13:2017.

[25] Wang, C. L. and Ahmed, P. K. (2005). The knowledge value chain: a pragmatic knowledge implementation network. Handbook of Business Strategy 6 (1): 321-326.

[26] Yoon B, Lee K, Lee S, Yoon J. Development of an R\&D process model for enhancing the quality of R\&D: comparison with CMMI, ISO and EIRMA. Total Quality Management \& Business Excellence. 2015 Aug 3;26(7-8):746-61.

[27] Kalypso, Manage R\&D as a Business: R\&D Management Framework accessed from http://viewpoints.io/uploads/files/RnDManagement.pdf, on 8 April 2021.

[28] Martin. Research and Development (R\&D), Overview and Process, Cleverism, 2014 accessed from https://www.cleverism.com/rd-researchand-development-overview-process/ on 8 April 2021.

[29] Rousselon PA, Saadn KN, Erickson TJ. The evolution of third generation R\&D. Planning Review. 1991 Feb 1.

[30] Yoshikawa H. Design methodology for research and development strategy. Japan: Center for Research and Development Strategy (CRDS). 2012 Feb.

[31] Joe C, Yoong P, Patel K. Knowledge loss when older experts leave knowledge-intensive organisations. Journal of Knowledge Management. 2013 Oct 18;17(6):913-27.

[32] Hammer M. The Getting and Keeping of Wisdom. Canada: Public Service Commission of Canada. 2002 Oct.

[33] Hinds PJ, Pfeffer J. Why organizations don't "know what they know": Cognitive and motivational factors affecting the transfer of expertise. Sharing expertise: Beyond knowledge management. 2003:3-26.

[34] Sulaiman MS, Nordin A, Noor NL. A review of knowledge retention frameworks for knowledge intensive organization. In2016 International Conference on Information Management and Technology (ICIMTech) 2016 Nov 16 (pp. 106-111). IEEE. 